\title{
Penerapan Arsitektur Metafora Dalam Redesain Pasar Wisata Plaosan Kabupaten Magetan
}

\author{
Annisa' Qurrotu'aini ${ }^{1 *}$, Sumaryoto ${ }^{2}$, Ofita Purwani ${ }^{3}$ \\ Arsitektur, Fakultas Teknik, Universitas Sebelas Maret ${ }^{1}$ \\ annisaqurrotuaini25@gmail.com* \\ Arsitektur, Fakultas Teknik, Universitas Sebelas Maret $^{2}$ \\ Arsitektur, Fakultas Teknik, Universitas Sebelas Maret $^{3}$
}

\begin{abstract}
Plaosan Tourism Market is the only tourism market at Magetan. This market has a potential to be a tourism destination at Magetan because it is located on the tourist route that head towards the popular attractions in Magetan. However this market is not a real tourism market as it does not meet the requirements for tourist destination which include attractions and facilities. This market does not use the potential of the area provided as attractions, even though Magetan is famous for farming and home industries. The market does not have primary and ancillary facilities to fulfill the tourism aspect. Besides the lack of attractions and facilities, the architecture of the market needs something unique on its design to attract the tourists. The design method used to redesign Plaosan Tourism Market is metaphoric architecture, because it can representate and show unique image, so it can attract tourists. The main problems in planning and designing Plaosan Tourism Market with metaphoric architecture approach ie what kind of attractions are needed in Plaosan Tourism Market, how the concept of facilities that requires tourism aspect, what form it will be used as basis of analogy that represents tourist destinations in Magetan, how to transform the base concept to be a tourism market design with metaphoric architecture. The planning and designing of Plaosan Tourism Market with metaphoric architecture approach use creative thinking method which consists of synthesising, elaborating, and imagining. Based on questionnaries, preferred objects to represent Magetan are Sarangan lake, leather handicrafts, Lawu mountain, and Batik Pringsedaphur, all of which will be to the main idea for the design by turning them into metaphor in designing this tourism market.
\end{abstract}

Keywords: redesign, tourism market, metaphor architecture, creative thinking, Magetan.

\section{PENDAHULUAN}

Pasar Wisata Plaosan terletak di kaki Gunung Lawu, Kabupaten Magetan, Jawa Timur tepatnya di Jalan Raya Sarangan, dengan luas lahan $\pm 11687 \mathrm{~m}^{2}$. Kawasan pasar ini merupakan pasar tradisional sekaligus pasar wisata dan terminal angkutan umum. Komoditi dagang yang dominan yaitu kebutuhan masyarakat seperti sayur mayur, buah-buahan, bumbu-bumbu, ikan, daging, pakaian, perabot rumah tangga, hingga makanan khas Magetan. Waktu operasional pasar ini setiap hari dari pagi hingga sore hari. Pasar Wisata Plaosan menyuguhkan pelayanan tingkat Kecamatan Plaosan hingga ke Kabupaten Magetan. Komoditas yang diperdagangkan di pasar ini berasal dari Kecamatan Plaosan sendiri karena kecamatan ini memiliki potensi di bidang pertanian.

Pasar Wisata Plaosan ini merupakan satusatunya pasar wisata yang ada di Kabupaten Magetan. Namun di sisi lain pasar yang diberi nama pasar wisata ini belum mencerminkan sebuah pasar wisata. Hal ini dilihat dari komoditi dagang yang hanya seperti pasar tradisional dan belum mengarah ke kegiatan wisata. Jangkauan pelayanannya hanya sebatas lingkup kecamatan, padahal suatu pasar wisata seharusnya berpotensi untuk dipasarkan hingga lingkup internasional. Selama ini pengunjung pasar ini hanya warga sekitar Kecamatan Plaosan, belum terdapat wisatawan yang mengunjungi pasar ini. Jika dilihat dari lokasinya, pasar ini termasuk strategis sebagai 
pasar wisata karena berada di jalur wisata menuju obyek wisata yang ada di Kabupaten Magetan seperti Telaga Sarangan, Telaga Wahyu, Air Terjun Pundak Kiwo, dan Puncak Lawu.

Jika dievaluasi dengan teori destinasi wisata menurut Cooper et. al dalam Damster \& Tassiopoulos (2005) yang terdiri dari empat komponen utama yaitu atraksi, fasilitas, aksesibilitas, dan layanan tambahan, terdapat kesenjangan pada komponen atraksi dan fasilitas. Hal tersebut dapat dilihat dari atraksi yang belum mengarah ke kegiatan wisata, serta fasilitas yang memenuhi kebutuhan wisata.

Oleh karena itu, perlu dilakukan redesain Pasar Wisata Plaosan sebagai upaya perbaikan komponen atraksi dan fasilitas agar memenuhi kebutuhan wisata. Perbaikan atraksi mencakup perbaikan komoditi dan kegiatan yang menarik yaitu dengan pemanfaatan potensi-potensi lokal yang ada di Kabupaten Magetan seperti hasil industri kerajinan. Selain perbaikan komoditi dan fasilitas, pasar ini butuh sesuatu yang unik pada desain bangunan untuk dapat menarik wisatawan, karena fitur fisik yang unik merupakan faktor utama yang menjadi daya tarik wisatawan (Fathimath, 2015). Oleh karena itu metode desain yang digunakan dalam redesain Pasar Wisata Plaosan adalah arsitektur metafora, karena dengan metode ini diharapkan dapat menampilkan bangunan yang unik yang dapat menarik pengunjung.

Permasalahan dalam perencanaan dan perancangan Redesain Pasar Wisata Plaosan dengan Pendekatan Arsitektur Metafora di Kabupaten Magetan antara lain atraksi wisata apa saja yang diwadahi dalam Pasar Wisata Plaosan Kabupaten Magetan? Bagaimana konsep kebutuhan ruang yang sesuai dengan pemenuhan aspek wisata dalam Pasar Wisata Plaosan Kabupaten Magetan? Bentuk apa yang diambil untuk dimetaforakan yang merepresentasikan pasar wisata sebagai destinasi wisata di Kabupaten Magetan? Bagaimana mengolah bentuk dasar menjadi desain pasar wisata dengan pendekatan arsitektur metafora?

Tujuan dari studi ilmiah ini yaitu dapat mendesain Pasar Wisata Plaosan dengan
Pendekatan Arsitektur Metafora di Kabupaten Magetan.

\section{METODE}

\subsection{Aspek komponen wisata}

Metode yang digunakan untuk mencari atraksi yang diwadahi yaitu kuesioner untuk menjaring ekspektasi masyarakat secara langsung tentang apa yang menjadi daya tarik mereka saat berkunjung ke tempat wisata. Sasaran kuesioner yaitu masyarakat umum khususnya masyarakat Jawa Timur dan Jawa Tengah yang pernah mengunjungi Kabupaten Magetan maupun yang belum pernah. Berdasarkan survey daya tarik yang ditujukan ke wisatawan Kabupaten Magetan, komoditi ekspektasi wisatawan tentang kerajinan kulit sebanyak $77 \%$, batik $48 \%$, kerajinan anyaman bambu $41 \%$, strawberry 35\%, jeruk Pamelo $33 \%$, gamelan $19 \%$, dan lainnya $5,4 \%$.

Metode yang digunakan untuk mengetahui fasilitas apa yang dibutuhkan untuk kegiatan utama maupun penunjang dilakukan studi preseden terhadap obyek yang sejenis maupun objek tidak sejenis namun masih terkait dengan kegiatan wisata. Preseden yang digunakan yaitu Pasar Beringharjo, Pasar Wisata Jatim Park I, Pasar Apung Nusantara Museum Angkut, dan Pasar Seni Gabusan.

\subsection{Arsitektur Metafora}

Metafora dimaksudkan sebagai bahasa arsitektural. Menurut Jencks (1977), orang dalam melihat suatu bangunan dapat membandingkan dengan benda serupa. Menurut Lakoff \& Johnson dalam (Mansilla, 2003), metafora adalah mekanisme analogi [...]. Terdapat beberapa cara dalam perancangan metafora atau analogi desain, salah satunya adalah creative thinking. Menurut (Mahmoodi, 2001) terdapat tahapan desain dalam creative thinking yaitu synthesising, elaborating, dan imagining.

Synthesising merupakan proses analisis dengan mengumpulkan data-data yang digunakan untuk menentukan ide desain. Dalam perancangan Pasar Wisata Plaosan ini proses synthesising dilakukan dengan cara survey tentang objek yang merepresentasikan Kabupaten Magetan. 
Berdasarkan hasil kuesioner, obyek yang merepresentasikan Kabupaten Magetan adalah Telaga Sarangan sebanyak 93,2\%, Kerajinan kulit 50\%, dan Puncak Lawu 27,3\%. Dari semua obyek yang ada, hal yang paling diingat oleh responden yang paling dominan adalah panorama dan hal-hal yang ada di Telaga Sarangan (misalnya: suasana alamnya, pegunungan, pohon cemara, perahu, sate, dan pulaunya), produk kerajinan kulit (misalnya: sepatu, tas, ikat pinggang, dll), serta motif bambu pada Batik Pringsedapur. Berdasarkan hasil survey, obyek-obyek tersebut akan diabstraksikan menjadi ide bentuk awal.

Metafora yang digunakan yaitu tangible metaphors (metafora yang dapat dirasakan secara visual). Dalam menentukan langkah desain metafora tangible dilakukan studi preseden. Preseden yang digunakan yaitu Museum Guggenheim Bilbao, Museum Tsunami Aceh, dan Sidney Opera House. Kesimpulan dari studi preseden yaitu obyek yang dimetaforakan tidak hanya mengambil dari satu obyek saja melainkan kombinasi dari berbagai obyek, dan obyek yang dimetaforakan biasanya mengambil atau menyesuaikan dengan tema bangunan atau lingkungan di mana bangunan berada.

Elaborating merupakan proses memperluas ide sehingga dapat dimodifikasi dari ide awal menjadi ide-ide desain, serta menggeser pandangan agar tidak terikat pada satu ide namun pada ide-ide lain yang dapat dikembangkan lagi.

Proses ini merupakan proses di mana bentuk dasar yang telah diperoleh dikaitkan dengan analisis kebutuhan ruang serta analisis struktur dan konstruksi untuk menghasilkan bentuk baru hingga menjadi desain.

Imagining merupakan proses mengembangkan respon terhadap suatu masalah dan mencari solusi dari permasalahan sehingga dapat memvisualisasikan solusi tersebut untuk mendapatkan keputusan desain.

\section{HASIL DAN PEMBAHASAN}

\subsection{Peruangan}

Berdasarkan kuesioner tentang atraksi wisatawan diperoleh kegiatan utama yang akan diwadahi yaitu jual-beli produk kerajinan Magetan dan workshop pembuatan produk kerajinan, sehingga ruang yang dibutuhkan yaitu kios, los, ruang workshop, dan ruang pameran hasil workshop. Sedangkan untuk fasilitas penunjangnya yaitu terminal, foodcourt, area istirahat wisatawan, kios outdoor, taman bermain anak, danau yang dilengkapi dermaga, mushola, dan tempat parkir.

Dari program ruang tersebut diperoleh matriks hubungan ruang seperti berikut.

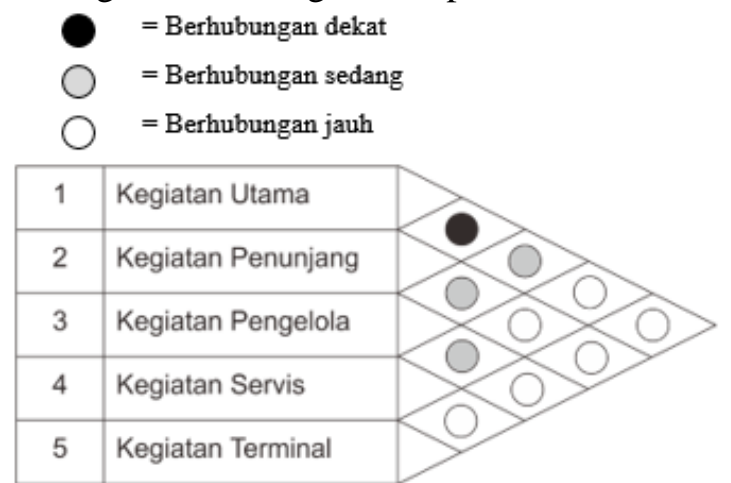

Gambar 1 Matriks Hubungan Ruang dalam Pasar Wisata Plaosan

\subsection{Tapak}

Lokasi Pasar Wisata Plaosan berada di Jalan Raya Sarangan, Kelurahan Plaosan, Kecamatan Plaosan, Kabupaten Magetan, Jawa Timur. Eksisting tapak merupakan kawasan pasar sekaligus terminal angkutan umum dengan luas tapak $\pm 11687 \mathrm{~m}^{2}$.

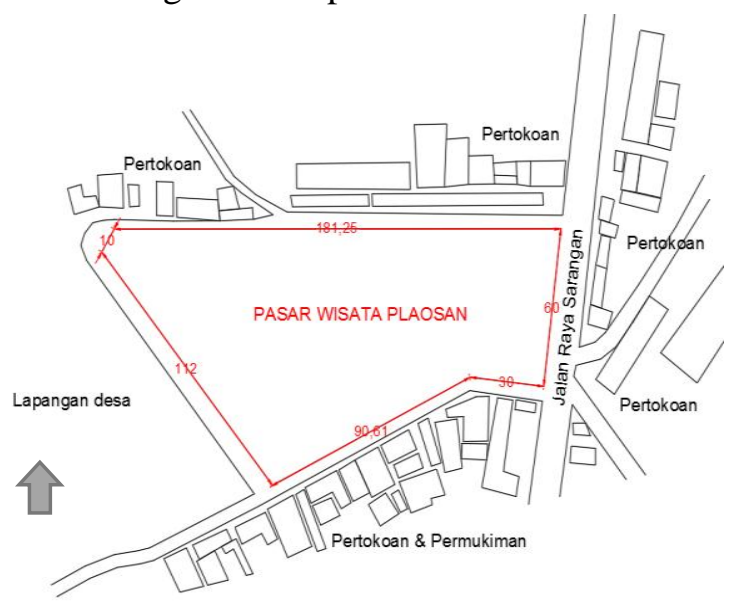

Gambar 2 Tapak Pasar Wisata Plaosan

Tapak Pasar Wisata Plaosan berpotensi untuk dikembangkan menjadi destinasi wisata karena berada di jalur utama perjalanan MagetanSolo; berada di jalur utama menuju obyek wisata alam yang ada di Kabupaten Magetan seperti Telaga Sarangan, Telaga Wahyu, Air 
terjun Pundak Kiwo, dan wisata Puncak Gunung Lawu; berada di ibukota Kecamatan Plaosan; berada di dekat desa sentra kerajinan batik tulis khas Magetan; berseberangan dengan Pasar Agrobisnis Plaosan; dan terintegrasi dengan Terminal Plaosan.

Konsep akses utama untuk menuju ke tapak yaitu melalui Jalan Raya Sarangan yang merupakan jalur utama, sedangkan untuk akses keluar tapak melalui jalan sebelah utara pasar untuk mengurangi kemacetan di jalur utama.

\subsection{Bentuk dan Tampilan Bangunan}

Berdasarkan survey dan studi preseden tentang arsitektur metafora, Pasar Wisata Plaosan akan dirancang dengan menggabungkan unsurunsur yang merepresentasikan Kabupaten Magetan.

Pengaplikasian bentuk danau yaitu bangunan dikelilingi kolam air sebagai representasi Telaga Sarangan. Kolam air ini dijadikan bagian dari area rekreasi outdoor.

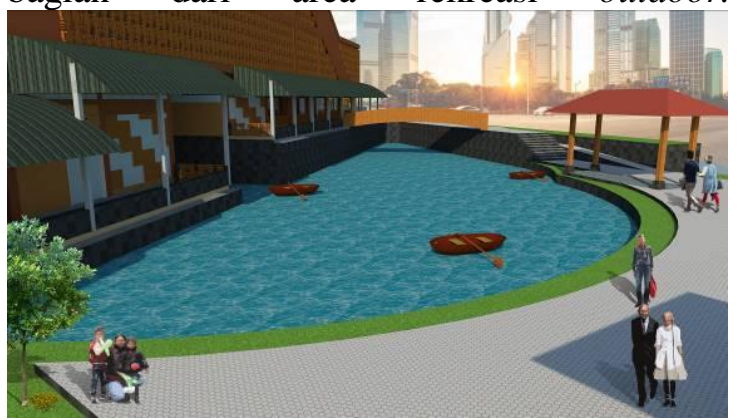

Gambar 3 Danau buatan sebagai representasi dari Telaga Sarangan

Bentuk dasar Gunung Lawu menjadi bagian dari bentuk massa bangunan utama khususnya pada lantai atas. Massa ini nantinya akan dijadikan sebagai ruang workshop dan ruang pameran.

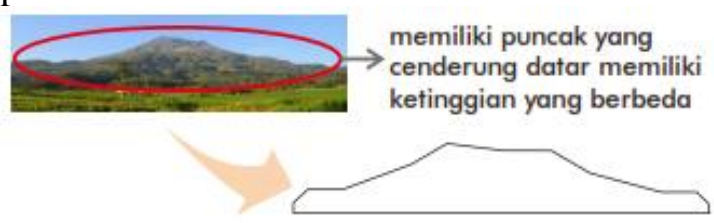

Gambar 4 Bentuk dasar Puncak Lawu

Bentuk sepatu yang digunakan yaitu sepasang sepatu untuk mendapatkan massa yang memanjang horizontal. Hal ini bertujuan untuk mendapatkan bentuk bagian atas sepatu yang menyatu satu sama lain dapat membentuk seperti gunungan. Jika dilihat dari depan terlihat seperti gunung dan jika dilihat dari perspektif yang berbeda bangunan terlihat seperti sepatu. Warna dasar kulit dijadikan warna bangunan secara keseluruhan. Massa ini kemudian dijadikan sebagai bangunan utama yang berisi kios-kios, foodcourt, ruang workshop, dan ruang pameran. Transformasi bentuk sepatu menjadi lebih geometris bertujuan agar bentuk massa dapat membentuk deretan ruang-ruang yang lebih efisien saat diisi dengan perabot, dan deretan ruang dapat membentuk sirkulasi linear. Selain itu hal ini untuk menciptakan massa bangunan yang lebih ramping sehingga sirkulasi udara dan pencahayaan dalam bangunan lebih optimal.

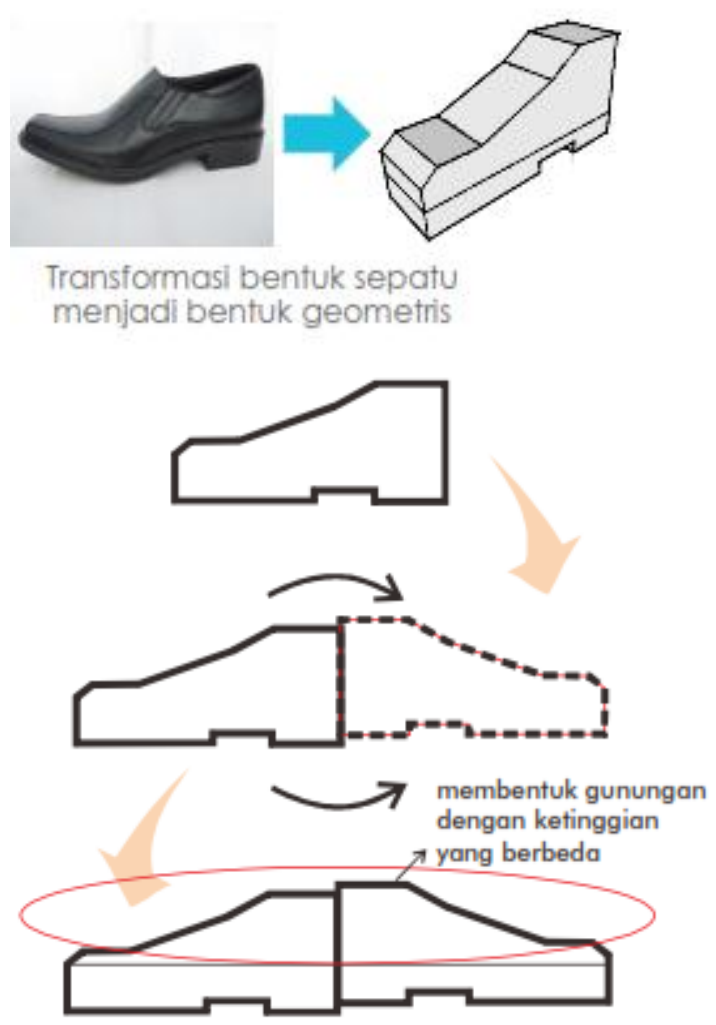

Gambar 5 Transformasi bentuk sepatu 


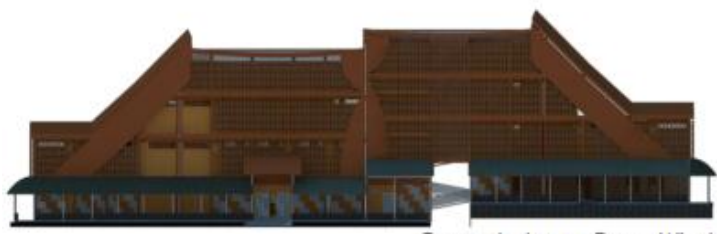

Gambar 6 Tampak Bangunan Utama

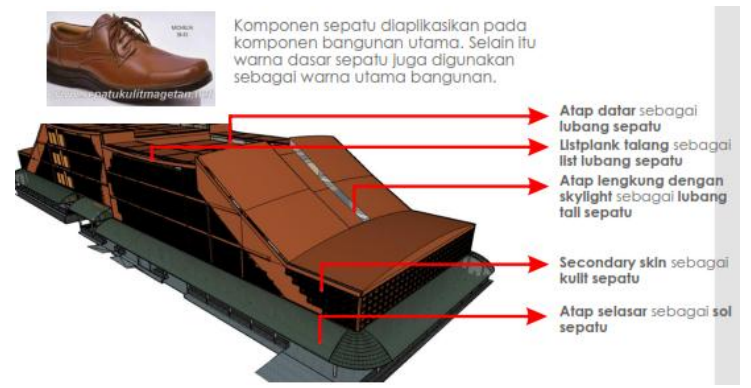

Gambar 7 Aplikasi komponen sepatu pada bangunan

Untuk menyesuaikan dengan bentuk tapak maka peletakan massa dalam tapak diposisikan miring ke belakang sekitar $60^{\circ}$, sehingga sudut pandang dari depan yang terlihat adalah bentuk sepatu dan dari samping terlihat seperti cerminan dari gunung.

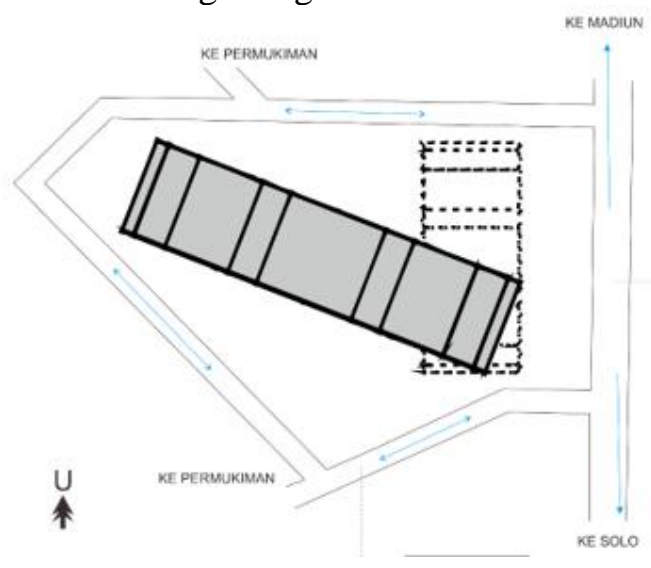

Gambar 8 Penyesuaian Massa pada Tapak Eksisting

Motif Batik Pringsedapur yang menggambarkan pohon bambu dijadikan bentuk ornamen pada dinding massa bangunan utama. Motif ini juga diaplikasikan sebagai secondary skin. Warna bambu yaitu coklat dijadikan warna dasar ornamen ini. Motif batik ini juga digunakan pada bentuk gapura masuk dan keluar kawasan.

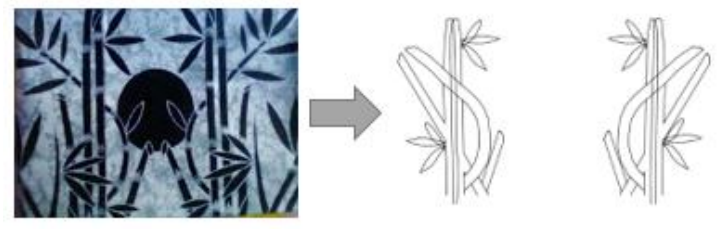

Gambar 9 Transformasi Motif Batik Pringsedapur

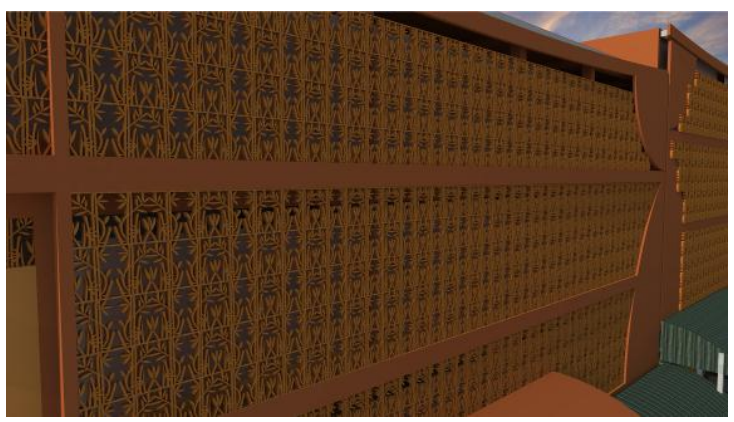

Gambar 10 Aplikasi Metafora Batik

Selain motif batik, pola anyaman bambu juga digunakan sebagai secondary skin sebagai kombinasi.

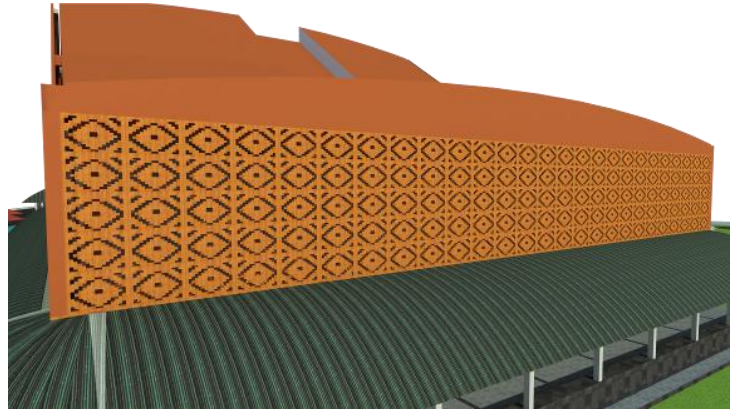

Gambar 11 Aplikasi Metafora Anyamana Bambu

Massa bangunan dengan pendekatan arsitektur metafora ini akan dijadikan sebagai massa bangunan utama dalam kawasan, sehingga direncanakan bangunan utama memiliki tiga lantai dengan massa yang memanjang horizontal yang dikelilingi fasilitas-fasilitas wisata outdoor seperti stand-stand, area istirahat pengunjung, danau yang dilengkapi dermaga serta jalur pejalan kaki yang dibuat mengelilingi kawasan agar penerapan arsitektur metafora dapat dilihat dari berbagai sisi. Hal ini bertujuan agar kawasan pasar wisata memiliki bangunan yang monumental dan terlihat menarik jika dibanding bangunan di sekitarnya. 


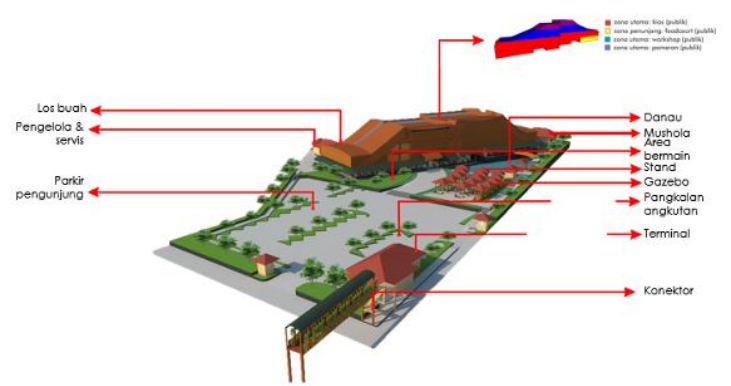

Gambar 12 Zona Kawasan Pasar Wisata

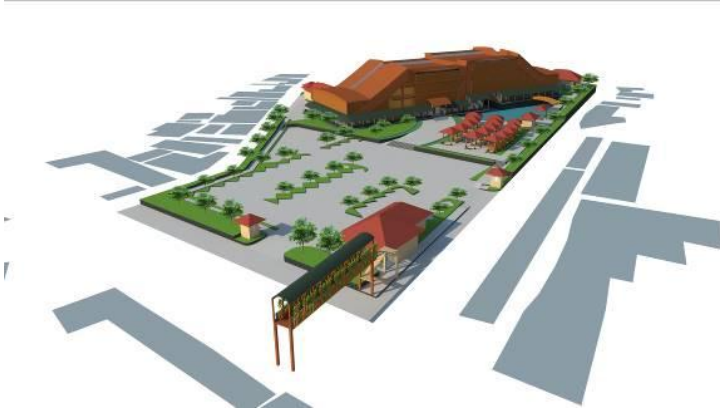

Gambar 13 Perspektif Kawasan Pasar Wisata Plaosan

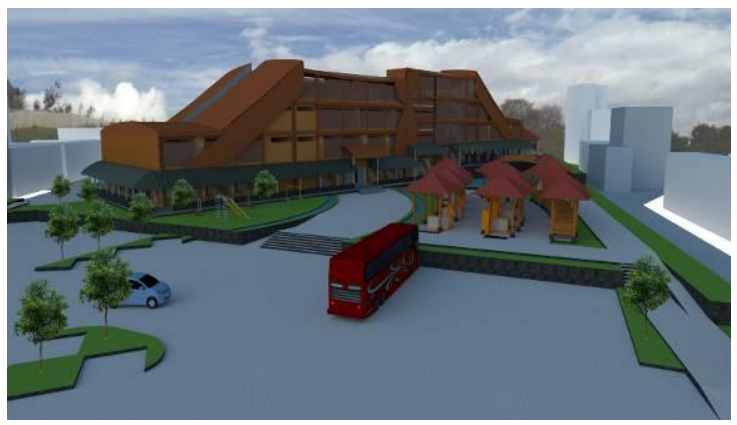

Gambar 14 Perspektif Bangunan Utama Pasar Wisata Plaosan

\section{KESIMPULAN}

Pasar Wisata Plaosan adalah wadah kegiatan jual beli barang yang memiliki daya tarik wisata di Kabupaten Magetan. Pasar wisata ini direncanakan dan dirancang kembali menjadi sebuah destinasi wisata dengan pendekatan arsitektur metafora. Arsitektur metafora merupakan arsitektur yang mampu merepresentasikan suatu obyek ke dalam bentuk bangunan.

Pasar Wisata Plaosan terletak di kaki Gunung Lawu, Kabupaten Magetan, dengan fungsi kawasan yaitu sebagai pasar tradisional sekaligus pasar wisata yang terintegrasi dengan terminal angkutan umum.
Atraksi yang diwadahi dalam Pasar Wisata Plaosan terdiri dari kegiatan jual-beli produk kerajinan yang ada di Kabupaten Magetan dan kegiatan workshop pembuatan kerajinan. Fasilitas utama Pasar Wisata Plaosan terdiri dari kios, los, ruang workshop, dan ruang pameran, sedangkan fasilitas penunjangnya antara lain terminal, foodcourt, area istirahat wisatawan, kios outdoor, taman bermain anak, danau yang dilengkapi dermaga, mushola, dan tempat parkir.

Pasar Wisata Plaosan dirancang dengan pendekatan Arsitektur Metafora. Tahap perencanaan dan perancangan arsitektur metafora menggunakan metode creative thinking yang terdiri dari tahap synthesising, elaborating, dan imagining. Metafora yang digunakan yaitu metafora tangible. Bentuk dasar metafora Pasar Wisata menggunakan obyek-obyek yang merepresentasikan Kabupaten Magetan. Obyek-obyek tersebut antara lain: Telaga Sarangan, Puncak Lawu, kerajinan kulit sepatu, motif Batik Pringsedapur, dan pola anyaman bambu.

\section{REFERENSI}

Damster, G., \& Tassiopoulos, D. (2005). Event Management: A Professional and Developmental Approach. Juta and Company Ltd.

Fathimath, A. (2015). The role of stakeholder collaboration in sustainable tourism competitiveness: the case of Auckland, New Zealand. Auckland University of Technology. Retrieved from https://aut.researchgateway.ac.nz/handle /10292/9272

Jencks, C. (1977). The Language of PostModern Architecture. Rizzoli.

Mahmoodi, A. S. (2001, September). The design process in architecture: a pedagogic approach using interactive thinking (phd). University of Leeds. Retrieved from http://etheses.whiterose.ac.uk/2155/

Mansilla, P. Ú. (2003). Metaphor at work: a study of metaphors used by European architects when talking about their projects. Ibérica, 5, 35-48. 